SANDIA REPORT

SAND96-0971 - UC-700

Unlimited Release

Printed April 1996
RECENED

MAY 151946

OSTI

\title{
Ultraminiature Resonator Accelerometer
}

Dale R. Koehler, Stanley H. Kravitz, Paul T. Vianco

Prepared by

Sandia National Laboratories

Albuquerque, New Mexico 87185 and Livermore, California 94550

for the United States Department of Energy

under Contract DE-AC04-94AL85000

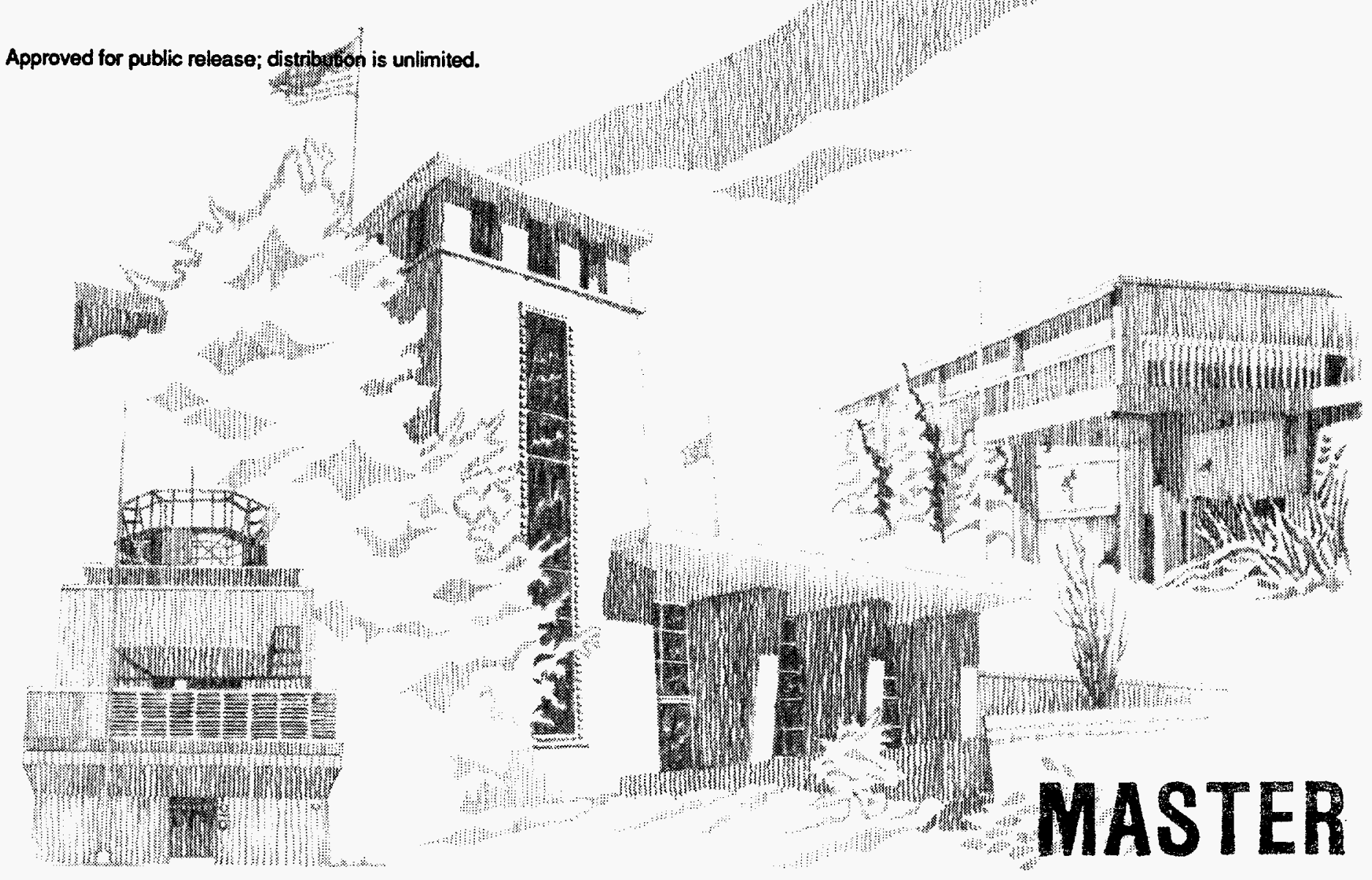


Issued by Sandia National Laboratories, operated for the United States Department of Energy by Sandia Corporation.

NOTICE: This report was prepared as an account of work sponsored by an agency of the United States Government. Neither the United States Government nor any agency thereof, nor any of their employees, nor any of their contractors, subcontractors, or their employees, makes any warranty, express or implied, or assumes any legal liability or responsibility for the accuracy, completeness, or usefulness of any information, apparatus, product, or process disclosed, or represents that its use would not infringe privately owned rights. Reference herein to any specific commercial product, process, or service by trade name, trademark, manufacturer, or otherwise, does not necessarily constitute or imply its endorsement, recommendation, or favoring by the United States Government, any agency thereof or any of their contractors or subcontractors. The views and opinions expressed herein do not necessarily state or reflect those of the United States Government, any agency thereof or any of their contractors.

Printed in the United States of America. This report has been reproduced directly from the best available copy.

Available to DOE and DOE contractors from

Office of Scientific and Technical Information

PO Box 62

Oak Ridge, TN 37831

Prices available from (615) 576-8401, FTS 626-8401

Available to the public from

National Technical Information Service

US Department of Commerce

5285 Port Royal Rd

Springfield, VA 22161

NTIS price codes

Printed copy: A03

Microfiche copy: A01 
7nownop

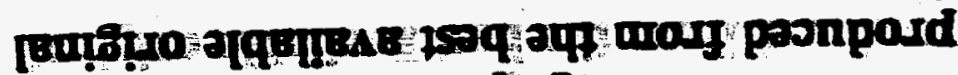

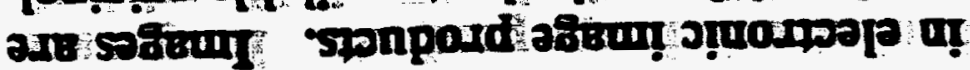

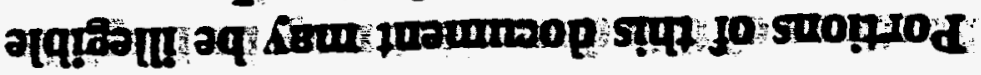
צENTYTDST 
SAND96-0971

Distribution

Unlimited Release

Printed April 1996

Category UC-700

\title{
Ultraminiature Resonator Accelerometer
}

\author{
Dale R. Koehler \\ Frequency and Optoelectronics Applications Department \\ Stanley H. Kravitz \\ Compound Semiconductor Technology Department \\ Paul T. Vianco \\ Physical and Joining Metallurgy Department \\ Sandia National Laboratories \\ Albuquerque, NM 87185
}

\section{Abstract}

A new family of microminiature sensors and clocks is being developed with widespread application potential for missile and weapons applications, as biomedical sensors, as vehicle status monitors, and as high-volume animal identification and health sensors. To satisfy fundamental technology development needs, a micromachined clock and an accelerometer (which represent classical program interests) have initially been undertaken as development projects. A thickness-mode quartz resonator housed in a micromachined silicon package is used as the frequency-modulated basic component of the sensor family. Resonator design philosophy follows trapped energy principles and temperature compensation methodology through crystal orientation control, with operation in the $20-100 \mathrm{MHz}$ range, corresponding to quartz wafer thicknesses in the 75-15 micron range. High-volume batch-processing manufacturing is utilized, with package and resonator assembly at the wafer level. Chemical etching of quartz, as well as micromachining of silicon, achieves the surface and volume mechanical features necessary to fashion the resonating element and the mating package. Integration of the associated oscillator and signal analysis circuitry into the silicon package is inherent to the realization of a size reduction requirement. A low temperature In and In/Sn bonding technology allows assembly of the dissimilar quartz and silicon materials, an otherwise challenging task. Unique design features include robust vibration and shock performance, capacitance sensing with micromachined diaphragms, circuit integration, capacitance-to-frequency transduction, and extremely small ( 0.1 in. square) dimensioning. Accelerometer sensitivties were measured in the 1-3 ppm/' $\mathrm{g}$ ' range for the milligram proofmass structures employed in the prototypes evaluated to date. 


\section{Contents}

A. Funding 1

B. Goals 1

C. Background 1

Original Proposal 2

1. Supporting Technologies 2

2. Technical Foundation and Innovation Evaluation 3

3. Programmatic Impact 9

D. Activity Categories 11

E. Technical Results and Discussion 11

F. Manufacturing plan 20

Appendix $\quad 22$ 


\section{Figures}

1. Block Diagram of the Sensor's Structural and Operational Concepts.

2. Acceleration Sensor............................................................................. 5

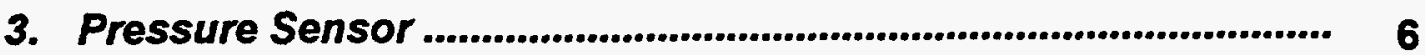

4. Chemical Sensor ........................................................................... 7

5. Wafer Fabrication and Assembly...................................................... 8

6. Applications .............................................................................................. 10

7. First Successfully Assembled Prototype Accelerometer Unit.

8. Accelerometer Constructional Schematic Illustrating Basic Features and Technology-Contributing SNL Departments.......... 15

9. Unit \#1 Accelerometer Performance.................................................... 16

10. Unit \#3 Acce/erometer Performance................................................ 17

11. Unit \#4 Accelerometer Performance................................................ 18

12. Hand held Unit \#3 with oscillator; 2-g Tipover Time Record Measurements.

13. Acceleration Sensitive Capacitor.................................................... 20

14. Manufacturing Plan............................................................................... 21

15. Accelerometer Block Diagram.................................................. 22

16. Timing Signals ........................................................................... 22 


\section{Ultraminiature Resonator Accelerometer}

\section{A. Funding}

This report covers the multiply funded accelerometer project, which has received budget support from the following sources:

1) Case 4706.400-Exploratory Components \& Subsystem Program Dept. 2602

2) Systems Center Case Support

3) Case 7073.400-Microelectronics and Photonics Program Dept. 1300.

\section{B. Goals}

The goals for this project were to design and develop an ultraminiature quartz resonator packaged with the oscillator IC and to configure the device to perform as an acceleration sensor for weapon, industrial, or medical applications.

For FY 95 the goals were as follows:

1. Develop a silicon proof-mass fabrication capability.

2. Investigate alternative gold proof-mass fabrication techniques.

3. Incorporate thin-film indium bonding for wafer assembly.

4. Develop silicon dry etching as an additional micromachining tool.

5. Construct low-stress diaphragms for more sensitive accelerometer designs.

6. Complete a viability demonstration for the accelerometer.

7. Complete a viability demonstration for the companion clock miniaturization technology.

\section{Background}

The original project was initiated in the summer of 1993. At that time, it was supported by the Microelectronics and Photonics Program, which was managed by Paul Peercy, 1300. In addition to support from this source, further support was provided by Michael Callahan, 2602, in the Exploratory Components and Subsystem Program.

The basic goal of this project, as outlined in the original proposal, was to develop a low-cost, rugged, quartz-resonator-based accelerometer. The proposal suggested that this could be achieved by utilizing a wafer-scale micromachined resonator process in conjunction with micromachined silicon proof-mass structures. The key to meeting this goal was thought to be 
the development of a method for making diaphragm-supported silicon proof masses, and several patent disclosures covering this area have been made. Brazing the covers onto the resonator was thought to be reasonably straight forward because an indium brazing process for achieving a quartz-to-silicon bond was under development for a companion integrated clock project.

Subsequently, additional support for the Miniature Resonator Accelerometer program was obtained from the Systems Center. The sponsor of this work was primarily interested in an accelerometer realization of the miniature resonator package. The sponsor agreed to provide program funding at the levels necessary to demonstrate viability and produce prototype units.

Because of the similarity of these programs and the extensive overlap between them, it made sense to combine them as far as program management and reporting were concerned. Success in the first program was critical to the success of the second program, and all of the activities on both programs were of vital interest to both sponsors.

The original proposal and whitepaper is included here as further project background information.

\section{ORIGINAL PROPOSAL}

\section{Supporting Technologies}

\section{Previous Years' Accomplishments}

We have developed silicon-wafer deep-well etching processes, necessary to silicon packages, and fabricated rudimentary silicon nitride diaphragm structures. We have also designed, developed, and demonstrated a miniature quartz-resonator technology and an associated CMOS-based oscillator technology.

\section{Work Proposed for First Year}

First year milestones include completion of the accelerometer design and analysis followed by procurement of resonator wafers. Simultaneously, an effort to refine and modify the thin-film silicon nitride diaphragm processing to accommodate silicon inertial mass fabrication has begun. The diaphragm effort is critical to the success of the accelerometer project and as such has constituted a technological go/no-go decision point for project viability and continuation. Completion of circuit modifications and analysis, and completion of the miniaturization designs are also planned accomplishments during this period. 


\section{Technical Foundation and Innovation Evaluation}

\section{Foundation}

A miniature thickness-mode quartz resonator serves as the fundamental measurand-sensing element for the sensor. Detection of frequency changes in quartz resonators has long been used as a digital technique to measure acceleration, as well as temperature, mass-loading, and vibration stimuli. As a thermometer, one uses crystal-orientation control to achieve linear, sensitive temperature dependence $\left(\sim 90 \mathrm{ppm} /{ }^{\circ} \mathrm{C}\right.$ with 0.1 millidegree resolution), which stems from the resonator's frequency-dependence on its elastic constants and physical dimensions. By contrast, the same orientation control has been used to effect temperature-stable resonators for precision frequency sources for clocks and timepieces. The AT-cut, or orientation, for example, has a zero first-order temperature coefficient and performs with less than a 10 -ppm frequency change over a $120^{\circ} \mathrm{C}$ temperature range. To minimize temperatureassociated dependencies, a temperature-stable crystalline orientation is used for the accelerometer, pressure sensor, and chemical sensor.

The operation of a vibrating piezoelectric plate can be understood in electrical terminology and analogy by reference to Figure 1. Electroding of the plate constitutes a quartz-dielectric parallel-plate capacitor and, via the piezoelectric effect in quartz, the transduction mechanism for stimulating the plate into mechanical motion. The classical electrical equivalents to the mechanical elements of the vibration, namely mass, elasticity, and friction, are displayed as $\mathrm{L}_{\mathrm{mot}}, \mathrm{C}_{\mathrm{mot}}$, and $\mathrm{R}_{\mathrm{mot}}$. When connected to an external electronic amplifying or oscillator element, the plate can be stimulated into oscillatory motion at any of the many possible platestructure resonances. Resonance selection is accomplished by electrode-patterning and crystal orientation control during manufacture. The oscillation frequency is dependent on the resonator characteristics to first order and on electronic characteristics to second order. In our ultraminiature resonator-oscillator structure, such an electronic element is constituted by an air-gap capacitor formed by one surface of the quartz plate and a second electrodeddiaphragm surface supported on the adjacent silicon cover. Perturbation of this capacitor element, in the case of an accelerometer realization, by inertial forces exerted on the massloaded diaphragm results in a perturbation of the oscillation frequency, thereby providing a digital measure of the acceleration field being sensed. 


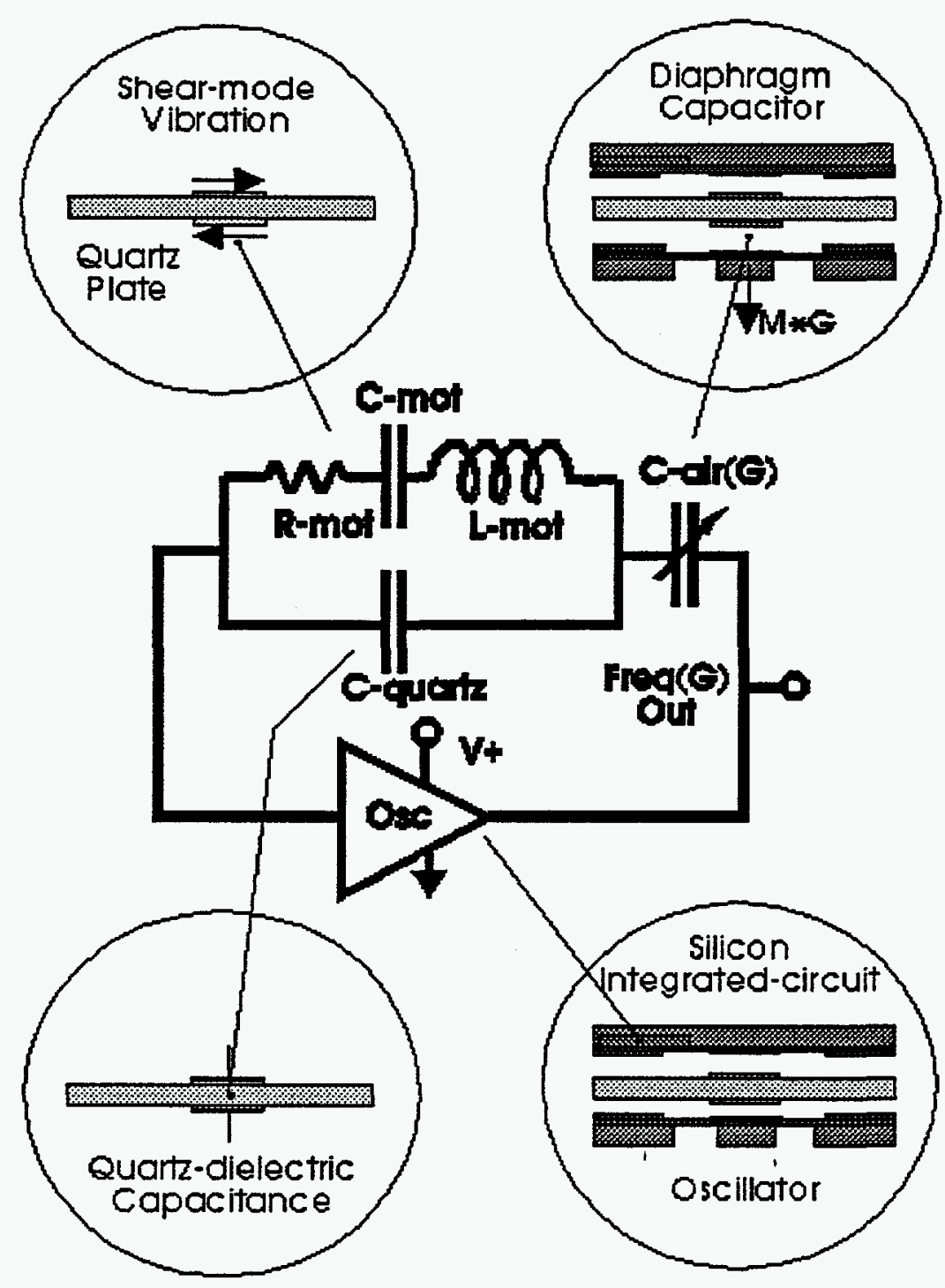

Figure 1. Block diagram of the sensor's structural and operational concepts.

As the physical dimensions of the resonator decrease, the static capacitance of the quartz plate, formed by the electroding on the main surfaces of the plate, also decreases and concomitantly the equivalent motional capacitance arising from the vibrational region between the electrode plates. Assuming no additional losses associated with the resonator size reduction, the associated equivalent motional resistance therefore increases. From an electronics perspective, an increasing resistance requires more electronic gain in the exciting circuitry, a requirement which dictates the range of operability of a given oscillator design. 
CMOS semiconductor technology is more restricted than bipolar technology in this regard. The miniature resonators fabricated to date have shown equivalent motional resistances in the range of $50 \mathrm{ohms}$ for a 1200 -micron-diameter resonator, to $125 \mathrm{ohms}$ for a 800 -microndiameter resonator, and to $450 \mathrm{ohms}$ for a 400 -micron-diameter resonator. Q, a measure of the losses in the resonator structure, has been measured in the 30,000 to 70,000 range. Our CMOS oscillators fabricated thus far have displayed a frequency capability to approximately $30 \mathrm{MHz}$ with an ability to drive 250 -ohm resonators.

Measuring resolution is primarily determined by the noise characteristics of the associated electronic oscillator in a resonator-based sensor system. With readily achievable short-term oscillator stabilities in the parts-per-billion range, excellent measurand resolutions are possible.

For the accelerometer, shown in Figure 2, response time is a function of the magnitude of the inertial mass and is longer for large mass, low " $G$ " designs. The supporting diaphragm constitutes the elastic restoring-force element and is design-variable through selection of the diaphragm thickness or its lateral dimensions.

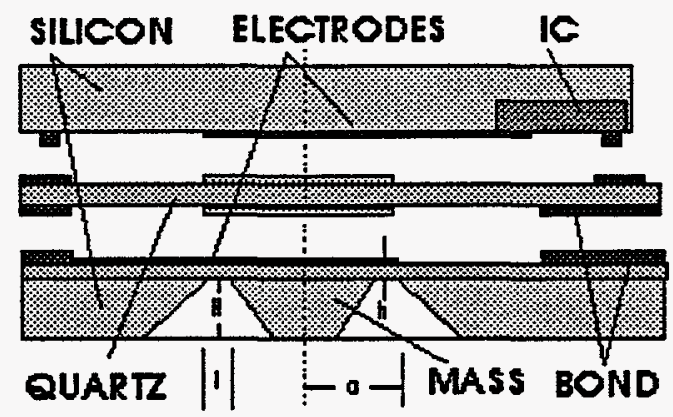

Figure 2. Acceleration sensor.

Design sensitivity to structural characteristics is evident in the deflection equations describing the response of a mass-loaded diaphragm to acceleration,

$$
\begin{array}{lr}
\Delta \text { gap }=S^{*} G & S=\frac{(H \rho g)}{(50.2 E)} \frac{a^{4}}{h^{3}} \\
\Delta f r e q=0.4 p p m / G & G \max =1000 G^{\prime} s
\end{array}
$$

(Untensioned silicon nitride diaphragm; $I=a / 2$, silicon mass)

$$
\mathrm{H}=625(10)^{-6}, \mathrm{a}=200(10)^{-6}, \mathrm{~h}=0.8(10)^{-6}, \rho=2.3(10)^{3}, \mathrm{E}=3.9(10)^{11}, \mathrm{~s}=.01 \mathrm{E}
$$


where $\Delta$ gap is the diaphragm deflection, $\mathbf{S}$ is the accelerometer sensitivity function, $\rho$ is the mass-density and $\mathbf{E}$ is the diaphragm modulus.

The pressure-measuring realization of the sensor structure, shown in Figure 3, is accomplished without the inertial mass, that is, with only a diaphragm enclosing the air-gap volume between the silicon substrate and the quartz resonator surface.

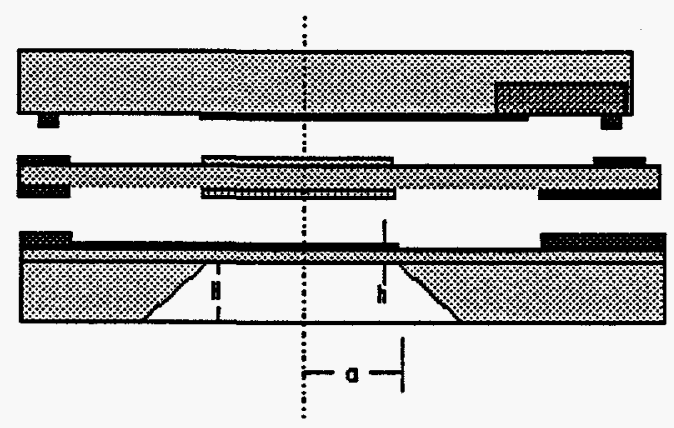

Figure 3. Pressure sensor.

Similar to the accelerometer example, design sensitivity to structural characteristics is shown in the deflection equations describing the response of a pressure-loaded diaphragm,

$$
\begin{gathered}
\Delta g a p=S * \Delta p \quad S=\frac{a^{2}}{(3 s h)} \\
\Delta f r e q=5 p p m / p s i \quad \Delta p \max =67 p s i \\
(\text { Tensioned silicon nitride diaphragm) } \\
H=625(10)^{-6}, a=200(10)^{-6}, \mathrm{~h}=0.8(10)^{-6}, \rho=2.3(10)^{3}, \mathrm{E}=3.9(10)^{11}, \mathrm{~s}=.01 \mathrm{E}
\end{gathered}
$$

where $\Delta \mathrm{p}$ is the pressure increment applied to the sensor diaphragm and $\mathbf{s}$ is the residual tension incorporated into the diaphragm material.

For the pressure sensor, response time is a function of the diaphragm's physical properties; density, tension, and dimensioning determine the vibrational and response time characteristics when the diaphragm behaves as a drumhead. Like the accelerometer, a pressure-induced capacitance change with a concomitant frequency modulation constitutes the digital measurand.

Chemical sensing requires exposure of the surface of the resonator to the chemical environment, shown in Figure 4, wherein adsorption of the chemical species of interest onto 
'sənb!̣uрә

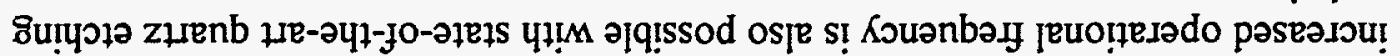

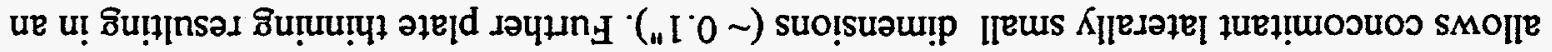

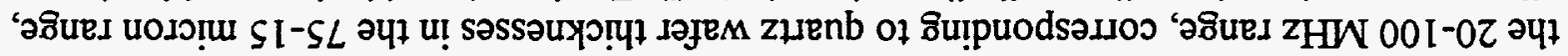

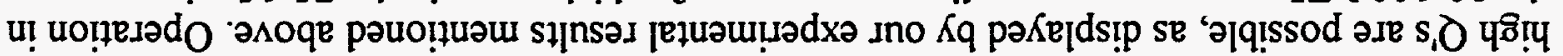

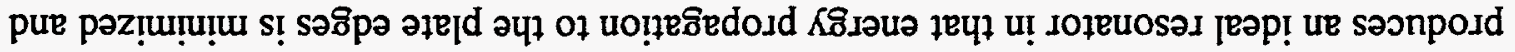

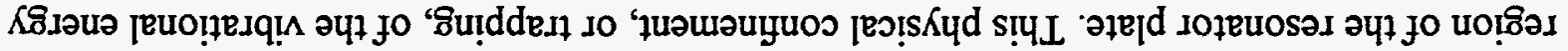

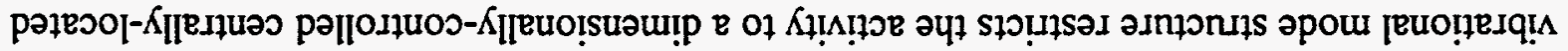
S, IOҢеUо

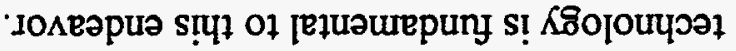

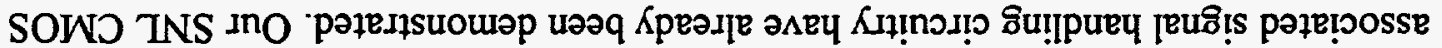

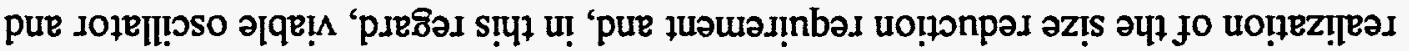

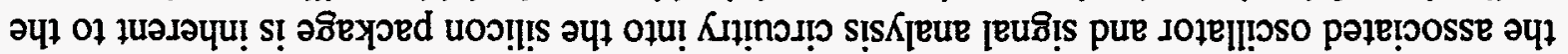

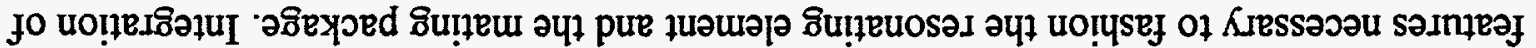

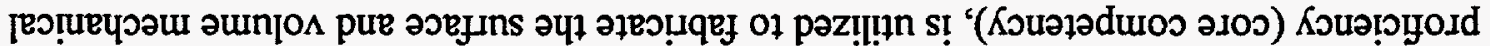

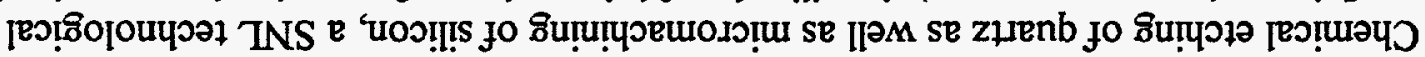

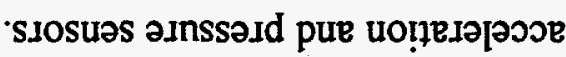

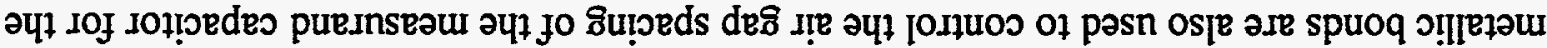

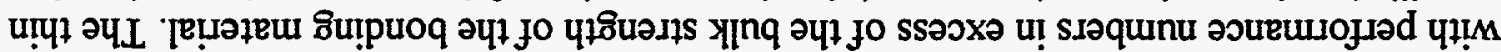

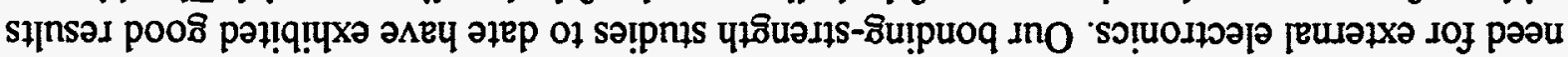

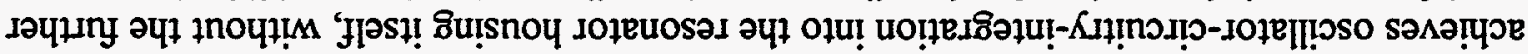

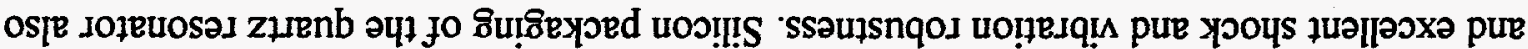

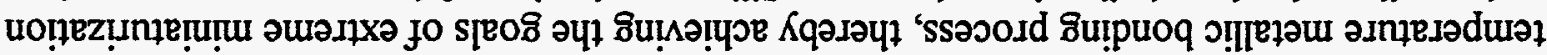

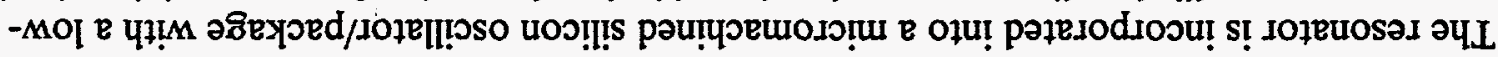

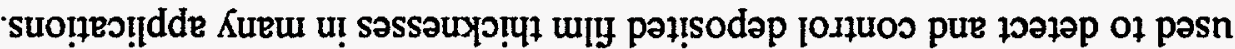

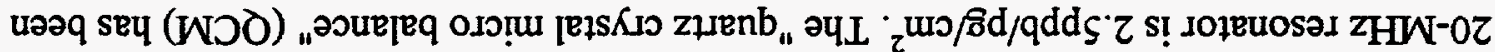

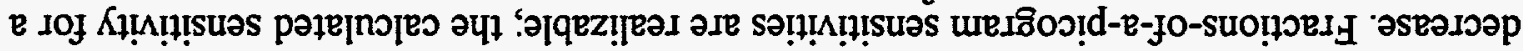

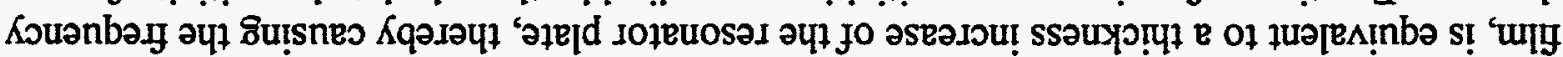

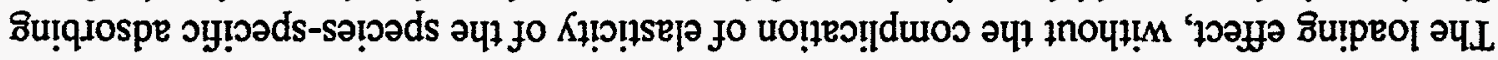

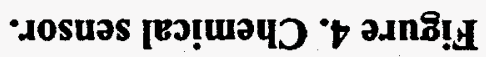

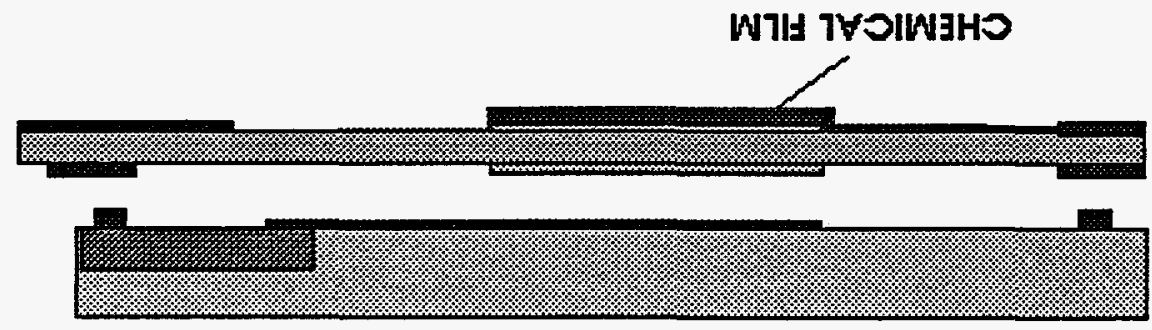

אouənbəy [euo!̣eıqu

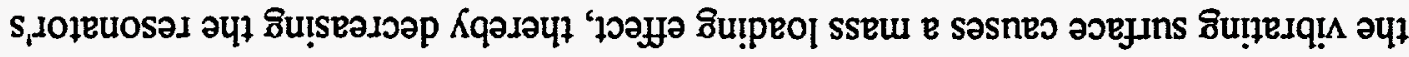


High-volume batch-processing manufacturing is utilized, with package and resonator assembly at the wafer level (illustrated diagrammatically in Figure 5). The SNL-developed thin-film In and $\mathrm{In} / \mathrm{Sn}$ bonding technology (also a core competency) allows low-temperature assembly of the dissimilar quartz and silicon materials, an otherwise challenging task since thermal expansion coefficients for $\mathrm{Si}$ and crystalline quartz differ by several $\mathrm{ppm} /{ }^{\circ} \mathrm{C}$.

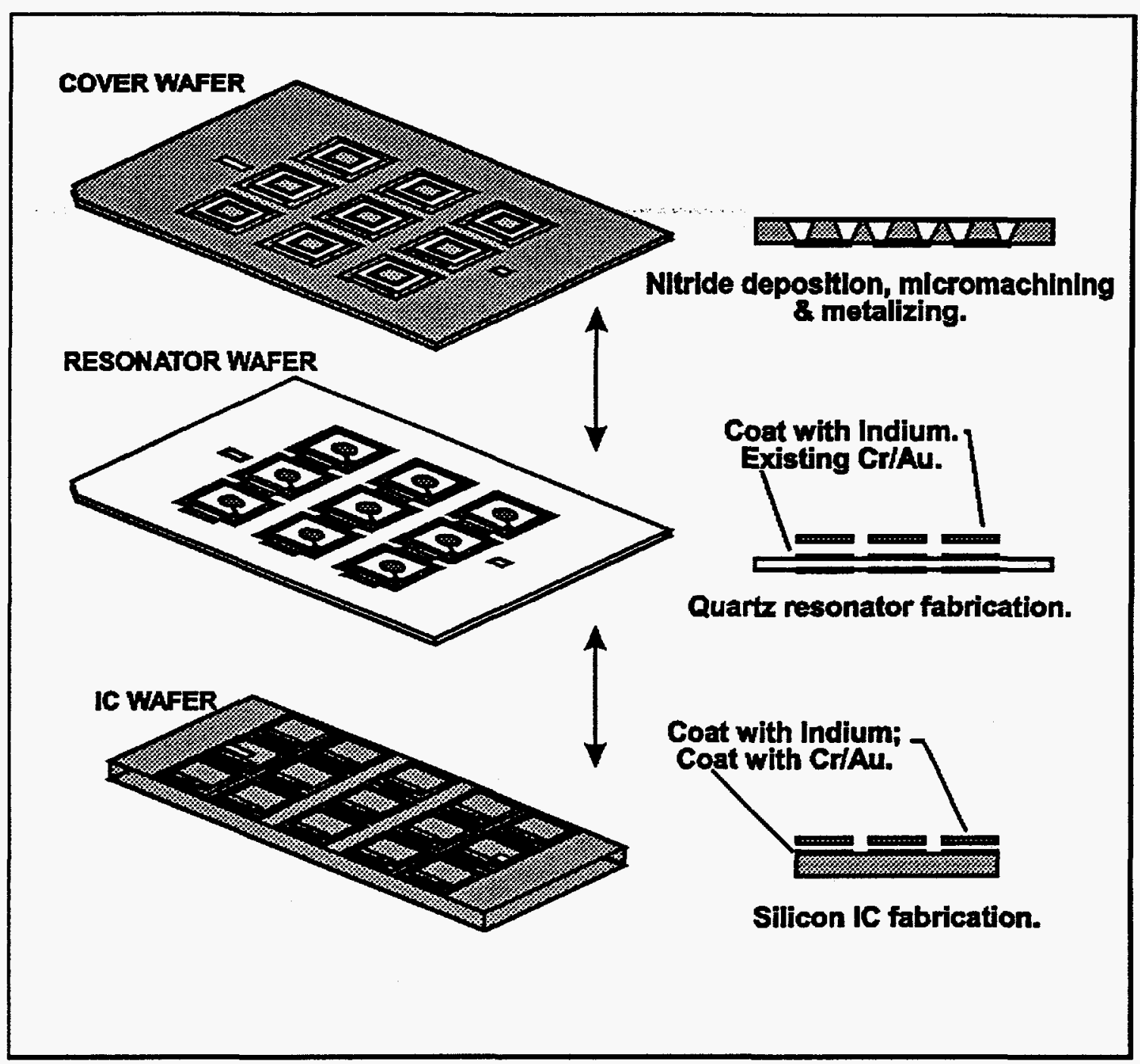

Figure 5. Wafer fabrication and assembly.

Innovation Evaluation

The miniature thickness-mode quartz resonator, the fundamental measurand-sensing element for the sensors, represents an advance over the state-of-the-art in quartz resonator fabrication. 
In conjunction with the fabrication of the associated packaging, these micromachined resonator structures represent the smallest such devices manufactured to date. Along with beacon realization concepts now patented (U.S. Patents \# 5,198,716 and 5,339,051), this SNL technology has been offered to US. Industry for commercial exploitation in several applications markets (now in Technology Transfer). Physical size is one of the more important driving factors in many applications and this advantageous feature of our ultraminiature sensor should afford it a strong competitive position in the commercial marketplace as well as in all weapons applications.

Inherent digital measurement methodology will offer superior performance over more conventional analog-measurand sensor techniques since frequency is one of the most precisely measurable physical quantities. With readily achievable short-term electronic oscillator stabilities in the parts-per-billion range, excellent resolution is possible. Analog micromachined silicon sensors are considered to be the primary competitive alternatives to the SNL quartz/silicon technology but digital readout manifestations of analog-based systems will require at least the additional burden of analog-to-digital conversion circuitry.

The innovative micromachined silicon oscillator/packaging concept achieves the goals of extreme miniaturization and excellent shock and vibration robustness. Silicon packaging of the quartz resonator also achieves the patented virtue of oscillator-circuitry-integration into the resonator housing itself, without the further need for external electronics. In addition to the use of high-volume batch-processing manufacturing of the component wafers, the subsequent package and resonator assembly at the wafer level affords additional technological and cost benefits.

A recent innovation, still in the development stage (disclosed for potential patent protection), would allow incorporation of a clock function into the same quartz-silicon structure constituting the sensor thereby providing a dual-measurand output. Similarly, using a temperature-sensor resonator would allow a temperature plus acceleration or temperature plus pressure dual measurand output. A triple-measurand design is also possible, as well as a platform construction, to provide an array of sensors. These new products should be considered as natural development extensions of the present program. For high-frequency applications and for high-resistance applications such as chemical sensing in liquids, a highgain resonator structure has been proposed, which would greatly reduce the electronic gain requirement and make more reasonable the possibility of integratable oscillator designs.

\section{Programmatic Impact}

This project relates to the "sensor," "microelectronics," and "frequency-control" technology areas. The quartz/silicon sensors (pressure sensor, chemical sensor, and accelerometer) will offer improvements over existing product capabilities in size, robustness, cost, and technical performance. The family of sensors realizable from these technological developments, furthermore, opens up a range of biomedical applications, as well as additional non-biomedical application areas such as the transportation, environmental monitoring, and animal monitoring fields. 


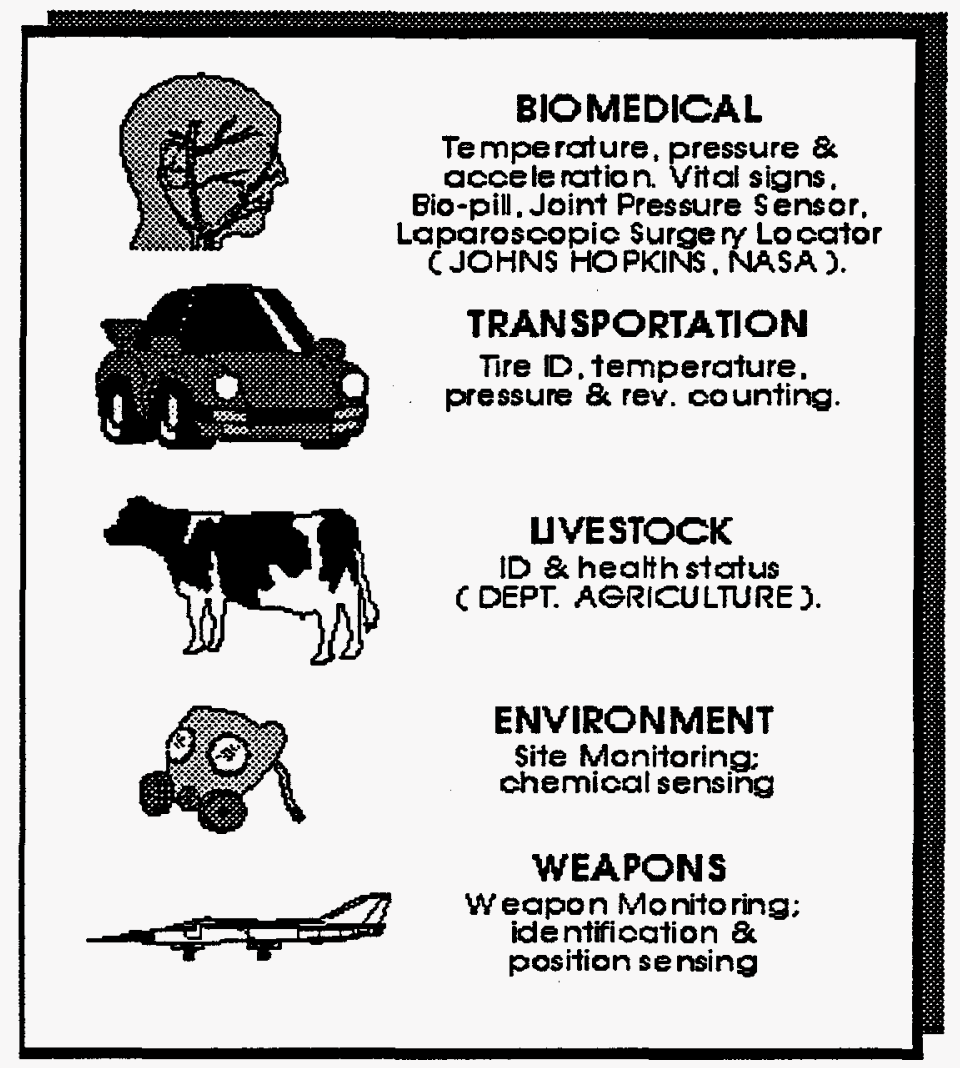

Figure 6. Applications.

The silicon micromachining and compatible silicon semiconductor fabrication technologies, in addition to the miniature quartz micromachining and low-temperature thin-film bonding technologies being advanced in this work, will extend our fundamental sensor expertise to provide still wider ranges of applicability. This work, therefore, integrates a broad range of technological capabilities. There is a significant improvement, in fact a patented improvement, over state-of-the-art capabilities manifested by the proposed work, which should greatly benefit the Laboratories in its industrial initiatives and in all sensor-demanding weapons applications, as well as in the sensor and frequency-control fields generally. 


\section{Activity Categories}

The project contains several major activity categories, some of which have been farmed out to other organizations. These major activity categories and the individuals and organizations working on them are outlined in the following table:

\begin{tabular}{|l|l|l|}
\hline Accelerometer Activities & Individuals & Organizations \\
\hline Overall Management & Dale Koehler & $\begin{array}{l}\text { Frequency and Optoelectronic } \\
\text { Applications }\end{array}$ \\
\hline Resonator \& Package Design & Dale Koehler & $\begin{array}{l}\text { Frequency and Optoelectronic } \\
\text { Applications }\end{array}$ \\
\hline Quartz Wafer Manufacture & Shih Chuang & Statek Corporation \\
\hline Silicon Wafer Micromachining & $\begin{array}{l}\text { Stan Kravitz } \\
\text { James Word }\end{array}$ & Compound Semiconductor Technology \\
\hline Braze Alloy Deposition & $\begin{array}{l}\text { Paul Vianco } \\
\text { Cathy Sifford }\end{array}$ & $\begin{array}{l}\text { Physical and Joining Metallurgy } \\
\text { Thin Film Brazing }\end{array}$ \\
\hline Brazing & $\begin{array}{l}\text { Paul Vianco } \\
\text { Chuck Walker }\end{array}$ & $\begin{array}{l}\text { Physical and Joining Metallurgy } \\
\text { Thin Film Brazing }\end{array}$ \\
\hline Electroplating & $\begin{array}{l}\text { David Norwood } \\
\text { Bob Stokes }\end{array}$ & Electronic Processing \\
\hline Dicing of Assemblies & $\begin{array}{l}\text { Kathy Myers } \\
\text { Nao Moore }\end{array}$ & Advanced Packaging \\
\hline Accelerometer Testing & Dale Koehler & $\begin{array}{l}\text { Frequency and Optoelectronic } \\
\text { Applications }\end{array}$ \\
\hline
\end{tabular}

\section{E. Technical Results and Discussion}

The individual activities pursued in this multiply funded program and their final status are detailed in the following.

Design of Accelerometer Prototype Package. An initial test package containing an array of three 22-MHz resonators and three silicon proof-mass/diaphragm structures was designed. The resonators and proof masses were designed to be capacitively coupled between quartz and silicon wafer levels. Two different proof masses were used and the third unit had no proof mass and was to be used as a reference. An MDL (microelectronics development lab) 
designed counter/oscillator CMOS prototyping circuit die was to be incorporated via dieattach and wire bonding to the quartz resonator wafer.

Procurement of 22-MHz Quartz Wafers. Wafers for this prototype were procured from Statek Corporation. All of the wafers were used for the various assembly and evaluation studies associated with the project.

Preparation of Silicon CMOS Oscillator Circuitry. Circuit wafers were successfully manufactured in the MDL with good yields and a substantial number of circuit dice are now available for use in prototype accelerometers as well as other sensor prototypes.

Fabrication of Micromachined Silicon Proof-Mass Wafers. Initial (April-July '94) silicon micromachining at the MDL evidenced diaphragm failures that precluded successful accelerometer construction. These problems were not solved, nor were MDL resources available to solve them. The MDL subsequently opted not to participate in our program, in particular, nor in bulk micromachining in general, preferring rather to concentrate technologically on surface micromachining. This lack of support caused a serious impact on the program. Our efforts to overcome this setback resulted in two alternative endeavors: (1) an attempt to fabricate electroplated gold proof masses on silicon nitride membranes in our Manufacturing Technologies Center, and (2) eliciting help from the CSRL (compound semiconductor research lab) to provide an alternative bulk silicon micromachining expertise.

Gold Proof-Mass Wafers. This activity required solving two major technical challenges. Because the gold deposition is a post-diaphragm-fabrication processing step, one must work with the diaphragm and associated deep silicon well already in place. This requires processes that do not damage the very thin diaphragms and it requires fashioning the proof-mass pellet inside the well. Deposition of a very thick ( $\cong 3$ mils) photoresist inside and outside the deep silicon well was finally accomplished. Photopatterning and resist etching of the thick photoresist was also successful. The photoresist process was necessary to define the physical extension of the electroplated gold. Provision of a thin conductive underlayer over the silicon surface prior to photoresist deposition was also necessary to effect the electroplating process. Both the electroplating and conductive-coating processes caused the diaphragm to malform with surface deformations of a magnitude comparable to the bond layer thickness, which was unacceptable. This problem was not solved within the time and budget constraints of the project.

Gold Proof-Mass Pellets. As an alternative to gold mass electroplating, a mechanical approach was also assessed for feasibility. This endeavor was accomplished with a punch-anddie approach, wherein the requisite physically sized gold masses were prepared in pellet form and subsequently adhesively bonded to the silicon nitride diaphragm. Although the pellet was successfully attached to the diaphragm, the bonding process caused the same diaphragm distension problem as the electroplated masses. This fabrication method was also abandoned.

CSRL Silicon Proof-Mass Wafers. The CSRL has proven to be an excellent support facility for the program. Masks were prepared and silicon etching successfully accomplished to produce the bulk-micromachined silicon-proof-mass structures for our accelerometer prototypes. Initial difficulties with diaphragm breakage were overcome and good wafers have since been delivered to us for accelerometer prototype assembly. Since the silicon wafers require an electrode and bonding metalization, in addition to the deep-well etching, an 
interrupted process was developed to accommodate a metalization step partway through the etching process.

Low-Stress Diaphragm Fabrication. Silicon nitride films are grown on silicon substrate wafers under conditions where the stoichiometry of the films can be controlled by gas flow. This fact allows one to further control certain physical properties of the resultant film. In particular, the index of refraction can be so controlled and, in fact, coated wafers can be purchased with index of refraction as a determining characteristic. In the case of silicon nitride on silicon, the internal residual film stress also varies with the stoichiometry and therefore one can effect film stress control when preparing coated wafers. In an accelerometer of the present design, film stress directly influences the sensitivity and one can therefore effect more or less diaphragm deflection sensitivity by proper selection of film stress or indirectly, film index of refraction. Since the index is a more readily measurable quantity, this is the specified characteristic. The coated silicon wafers successfully prepared for accelerometer use as described above were characterized as silicon-rich material with an index of refraction of $\mathrm{n}=2.25$ and with an associated film stress of $5(10)^{6} \mathrm{~N} / \mathrm{m}^{2}$. At this stress level, the diaphragm's elastic behavior is dominated by the film stress.

Silicon Dry Etching. Bulk silicon micromachining is limited in its feature shaping capability by the sensitivity of the wafer's crystalline planes that are exposed to the chemical etchants. In the present design, this means only rectangular wells and prismoidially shaped silicon proof masses can be realized. A more flexible shaping capability is afforded by dry etching where, for example, a circular disc shaped proof mass is possible. Such a dry-etching process has been put in place in the CSRL and now allows further design flexibility for fashioning silicon parts. Although our prototype fabrication plans called for some proof-mass construction with this technology, technician staffing problems have delayed this activity as of this writing $(3 / 1 / 96 ; \approx 2.5$ month interruption).

Companion Clock Fabrication Technology. Demonstration of functioning 22-MHz clocks has been achieved. This technology-companion project has been proceeding in parallel with the accelerometer prototype project and has been of considerable benefit to it. The quartz resonator wafer is indium-bonded to a silicon integrated circuit cover wafer and a second quartz cover wafer. Forty eight units have been fabricated to date. Excessively large output pads ( $20 \times 20$ mils) have been identified as the source of parasitic feedback capacitance and a tendency for the oscillator to free-run. This structural format, with a reduced pad layout, is planned for any follow-on applications of the accelerometer.

Quartz-Silicon Wafer Bonding and Assembly. A four-micron-thick indium film coat over an underlying $\mathrm{Cr} / \mathrm{Au}(200 / 1800 \mathrm{~A})$ double-layer is the bonding agent for both the accelerometer and the clock. The wafers are stacked on a pin-defined positioning fixture and placed in a programmable furnace. Several time-temperature profiles have been tried with varying degrees of success and profile optimization is still proceeding. The initial assembled accelerometer prototype units suffered from resonator wafer cracking and disallowed operation or evaluation since the cracks impacted both the resonators and the supporting electrode structures.

Project Hold. Due to lack of budget support, this accelerometer development activity was discontinued for the two-month period from 1 October '95 to 17 November '95. Subsequent 
redirection of other funds from the high-frequency resonator project has allowed restart of this effort.

Evaluation of Assembled Prototypes. Successful assembly of the first prototype was accomplished on 1/16/96. The larger of the two proof-mass diaphragms was ruptured; however acceleration characterization data was taken on the small-mass unit. Because of relatively large resonator resistances, the on-board CMOS oscillator was not able to drive the remaining units; neither the reference resonator with no proof mass nor the small-mass accelerometer unit. Acceleration sensitive frequency shifts were measured with an H.-P. impedance analyzer and are tabulated in the following pages. Subsequently, three additional prototypes were successfully assembled and characterization data were gathered on both large- and small-mass accelerometer units. Figure 7 is a photograph of one of the assembled prototypes.

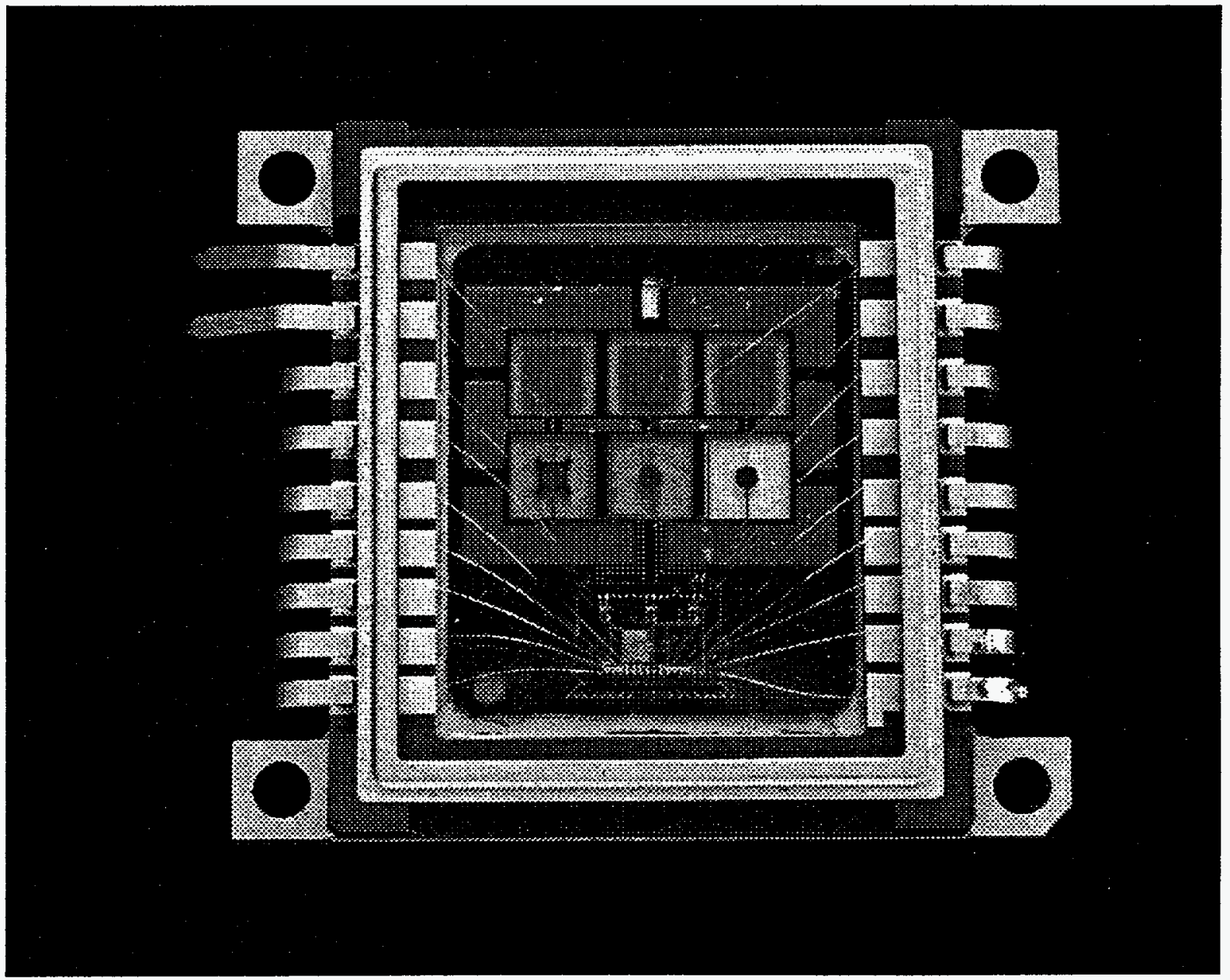

Figure 7. First successfully assembled prototype accelerometer unit. 
A "stressed diaphragm" or drumhead model of the "silicon nitride diaphragm/silicon proof mass air-gap capacitor" construction was utilized to theoretically calculate the expected deflection behavior and acceleration sensitivity of the resonator-accelerometer. In all cases the experimental sensitivity results were in fair agreement with the model but were consistently lower than the model calculations. Evaluation prototypes consisted of, in addition to the reference resonator structure, two different proof-mass versions; a small-mass element of $1310 \mu$ grams and a larger-mass element of $3180 \mu$ grams. Two small-mass units had sensitivities of 1.1 and $1.2 \mathrm{ppm} /{ }^{\prime} \mathrm{g}$ ' compared to theoretical expectations of 1.8 and 3.0 $\mathrm{ppm} / \mathrm{g}^{\prime}$ '. A single large-mass unit exhibited an experimental sensitivity of $2.8 \mathrm{ppm} /{ }^{\prime} \mathrm{g}$ ' compared with a theoretical calculation of $4.4 \mathrm{ppm} / \mathrm{g}^{\prime} \mathrm{g}$.

The equivalent circuit characteristics of these prototypes indicate a greater than expected motional capacitance and resistance. Both factors are explainable as an air gap larger than that supposedly generated by the 4-micron indium layer bonding the silicon proof-mass wafer to the quartz wafer. It is suggested that particulate contamination at the wafer interface is responsible and that better cleanliness control is necessary to eliminate and remedy the large air gap problem.

The constructional diagram and the experimental acceleration-characterization data are provided in Figure 8. Figures 9-11 display the acceleration sensitivities for three units. Unit \#2 was non-operational.

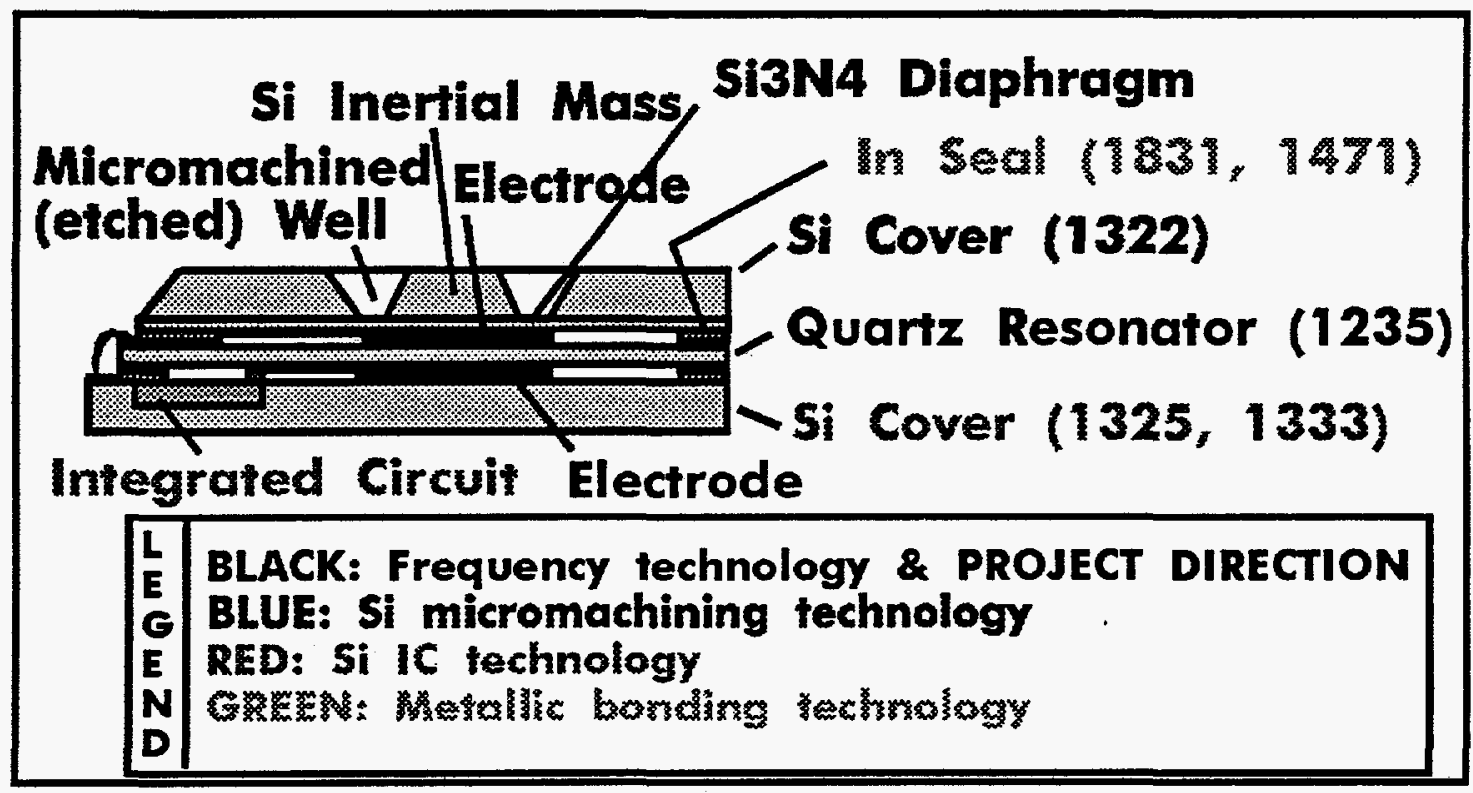

Figure 8. Accelerometer constructional schematic illustrating basic features and technology-contributing SNL departments. 


\section{UNIT \#1 ACCELEROMETER CHARACTERISTICS}

- Proof mass $=1310 \mu \mathrm{g}$. Air gap $=4 \mu$. Resonator freq. $=21,684,700 \mathrm{~Hz}$.

- Silicon nitride diaphragm @ $1 \mu$ thick. $x(4 \mathrm{~mm})^{2}$, stress = 5 MegaPascals.

\section{UNIT \#1 ACCELEROMETER RESONATOR EQUIVALENT CIRCUIT PARAMETERS}

- Motional resistance $=415 \Omega \quad$ Motional capacitance $=0.763416 \mathrm{fF}$

- Motional inductance $=70.5610 \mathrm{mH} \quad$ Static capacitance $=3.53148 \mathrm{pF}$

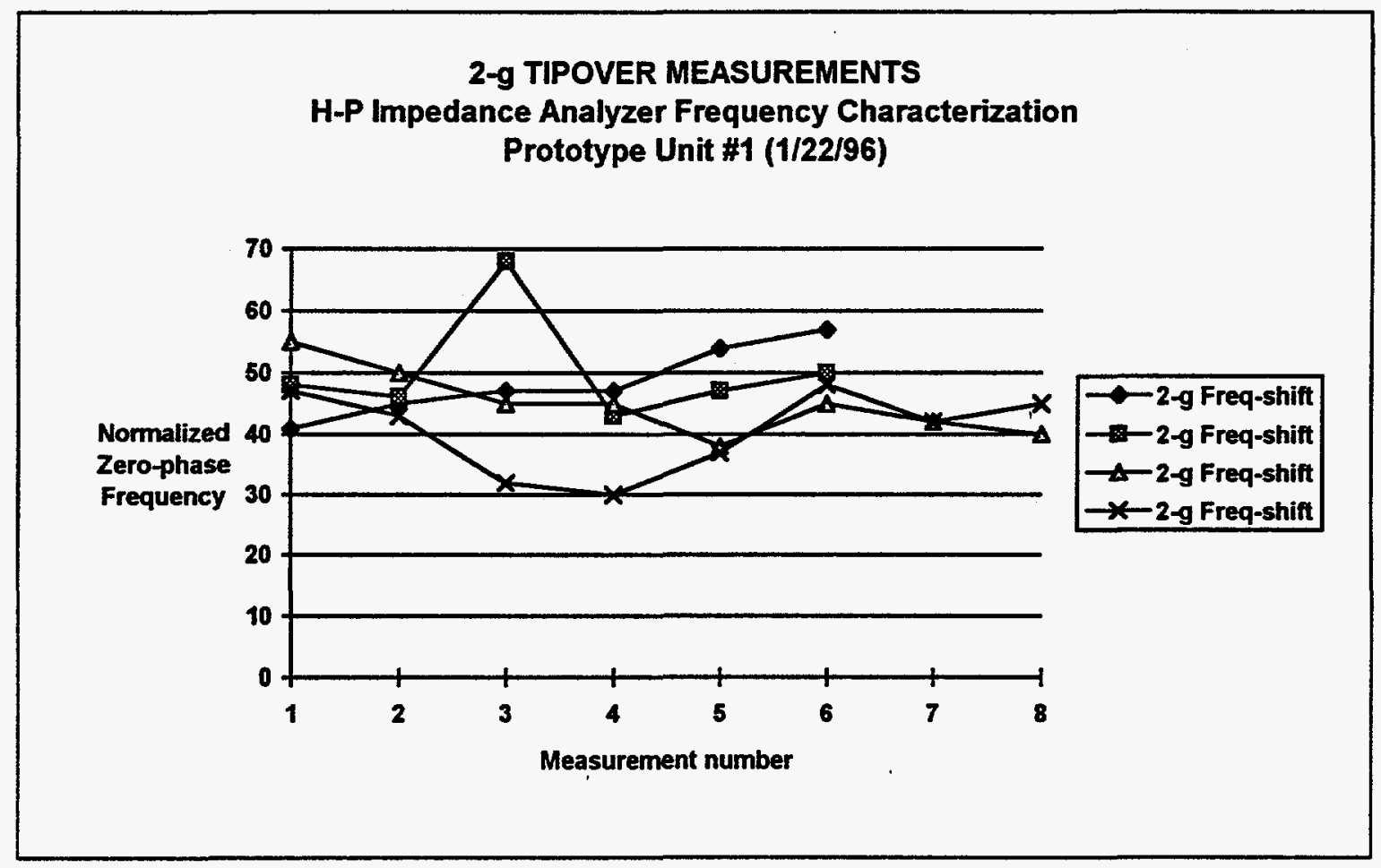

Figure 9. Unit \#1 Accelerometer performance.

- Average 2-g freq. shift $=46 \mathrm{~Hz}$; Standard deviation $=4.3 \mathrm{~Hz}$.

- Acceleration Sensitivity $=1.1 \mathrm{ppm} /$ ' $\mathrm{g}$ ';

Drumhead model calculation $=1.8 \mathrm{ppm} /{ }^{\prime} \mathrm{g}$ '. 


\section{UNIT \#3 ACCELEROMETER CHARACTERISTICS}

- Proof mass $=1310 \mu$ g. Air gap $=4 \mu$. Resonator freq. $=21,658,850 \mathrm{~Hz}$.

- Silicon nitride diaphragm @ $1 \mu$ thick. $x(4 \mathrm{~mm})^{2}$, stress= 5 MegaPascals.

\section{UNIT \#3 ACCELEROMETER RESONATOR EQUIVALENT CIRCUIT PARAMETERS}

- Motional resistance $=127 \Omega \quad$ Motional capacitance $=1.27548 \mathrm{fF}$

- Motional inductance $=42.3348 \mathrm{mH} \quad$ Static capacitance $=3.52891 \mathrm{pF}$

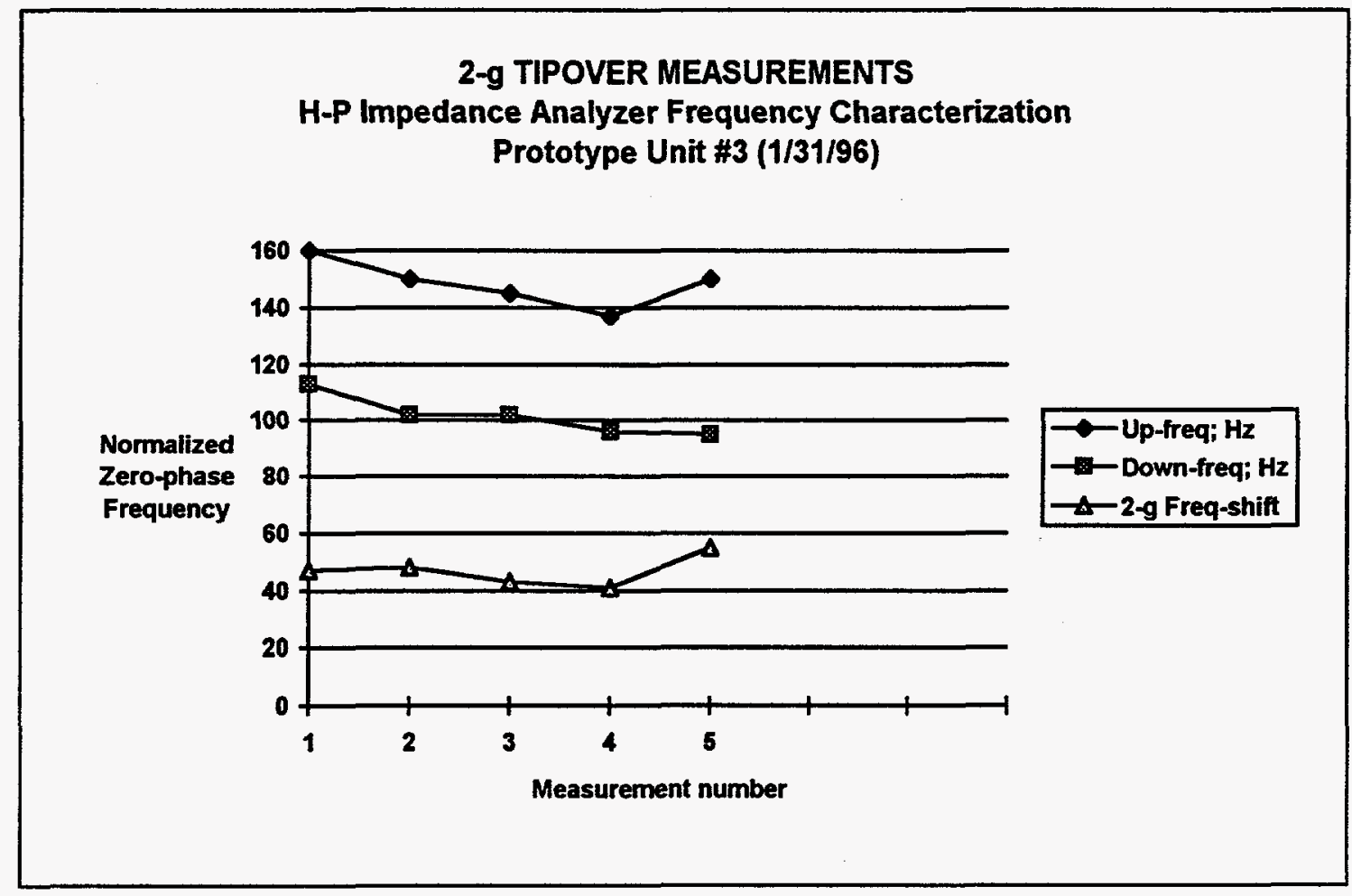

Figure 10. Unit \#3 Accelerometer performance.

- Average 2-g freq. shift $=50 \mathrm{~Hz}$; Standard deviation $=7.0 \mathrm{~Hz}$.

- Acceleration Sensitivity $=1.2 \mathrm{ppm} /{ }^{6} \mathrm{~g}$;

Drumhead model calculation $=3.0 \mathrm{ppm} /$ ' $\mathrm{g}$. 


\section{UNIT \#4 ACCELEROMETER CHARACTERISTICS}

- Proof mass $=3180 \mu \mathrm{g}$. Air gap $=4 \mu$. Resonator freq. $=21,677,700 \mathrm{~Hz}$.

- Silicon nitride diaphragm @ $1 \mu$ thick. x $(4 \mathrm{~mm})^{2}$, stress=5 MegaPascals.

\section{UNIT \#4 ACCELEROMETER RESONATOR EQUTVALENT CIRCUIT PARAMETERS}

- Motional resistance $=460 \Omega \quad$ Motional capacitance $=1.04536 \mathrm{fF}$

- Motional inductance $=51.5652 \mathrm{mH} \quad$ Static capacitance $=3.20606 \mathrm{pF}$

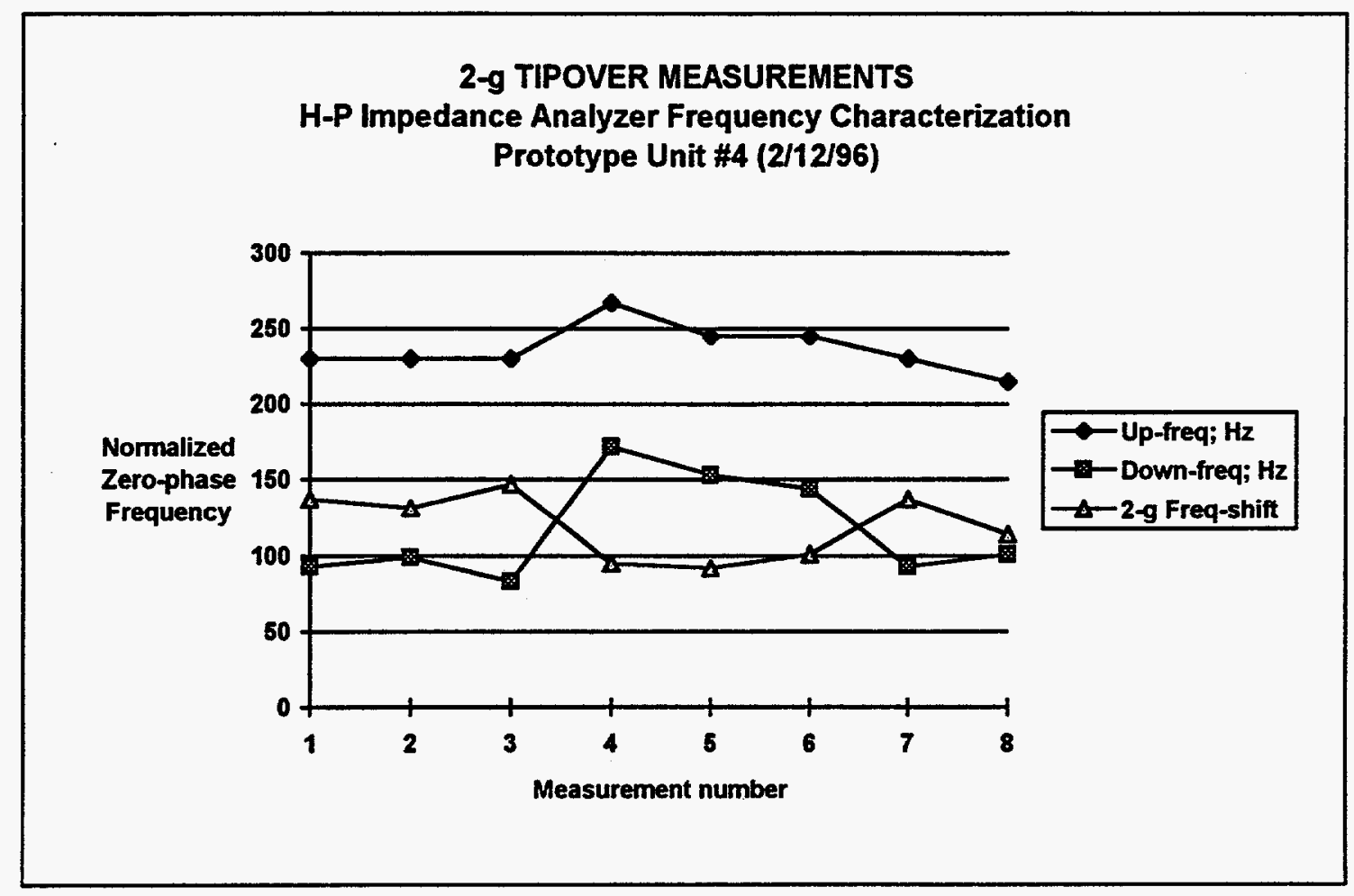

Figure 11. Unit \#4 Accelerometer performance.

- Average 2-g freq. shift $=119 \mathrm{~Hz}$; Standard deviation $=21 \mathrm{~Hz}$.

- Acceleration Sensitivity $=2.8 \mathrm{ppm} /{ }^{\prime} \mathrm{g}$ ';

Drumhead model calculation $=4.4 \mathrm{ppm} /$ ' $\mathrm{g}$ '. 
Finally, Figure 12 illustrates a time record of the changing accelerometer frequency during the transient produced when the resonator-accelerometer (unit \#3) is incorporated into a batterypowered ( 3 Volts) driving-oscillator and the unit is "tipped over" and "back", executing a 2-g transient of approximately two seconds in duration. The data were taken with a HewlettPackard Time-Frequency Analyzer Model 5371A on a 0.1 second time sampling basis. Measurement of the oscillator short term stability is limited to the precision of the $5371 \mathrm{~A}$.

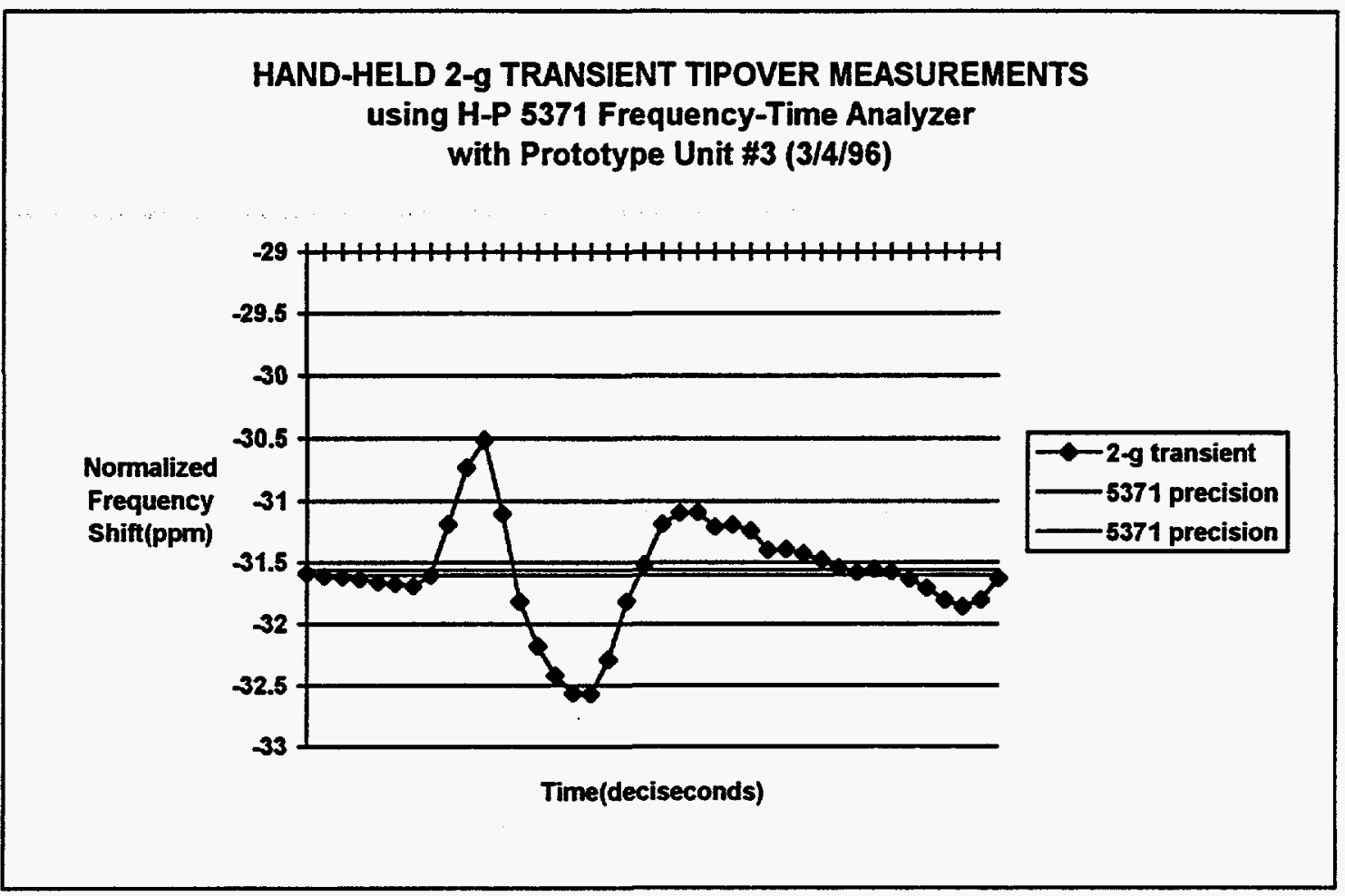

Figure 12. Hand held Unit \#3 with oscillator; 2-g Tipover Time Record Measurements. 


\section{F. Manufacturing Plan}

A manufacturing plan that utilizes the industrial production capability for bulk micromachining of silicon for an acceleration sensitive capacitor fabrication is illustrated in Figure 14. The capacitor is illustrated in schematic form in Figure 13. Utilization of an established quartz resonator/oscillator manufacturing capability is also depicted in Figure 14 for providing a miniature packaged frequency source. Assembly of the basic components into the final accelerometer configuration would be accomplished at SNL or the capacitor could be supplied to the resonator/oscillator manufacturer for assembly. A resonator/oscillator manufacturer's miniature package, which would constitute the entire accelerometer component, is approximately $20 \times 13 \times 6 \mathrm{~mm}$.

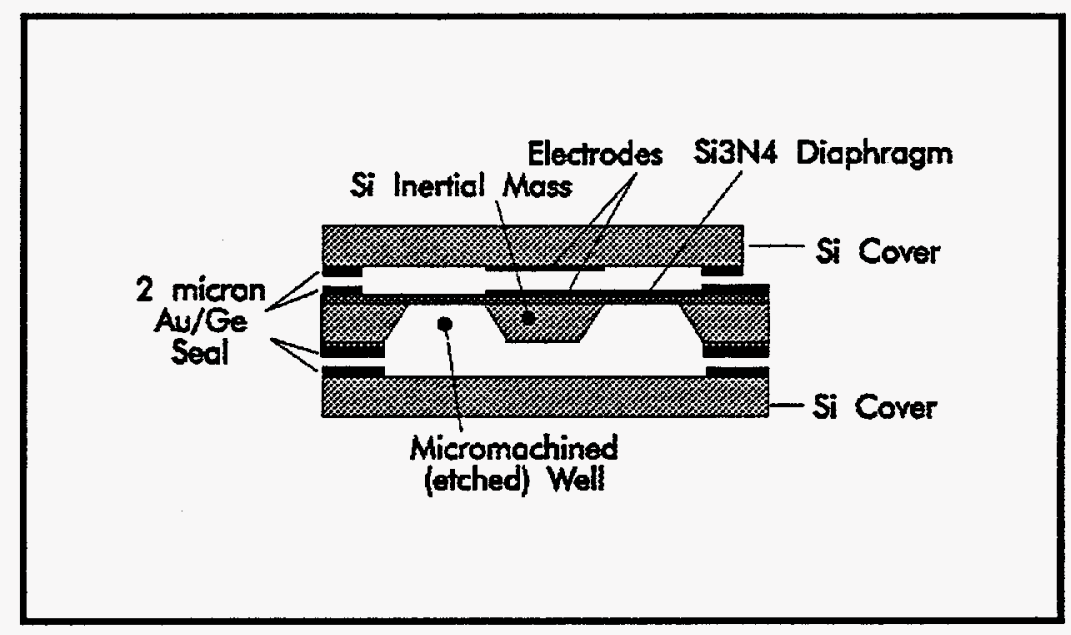

Figure 13. Acceleration sensitive capacitor. 


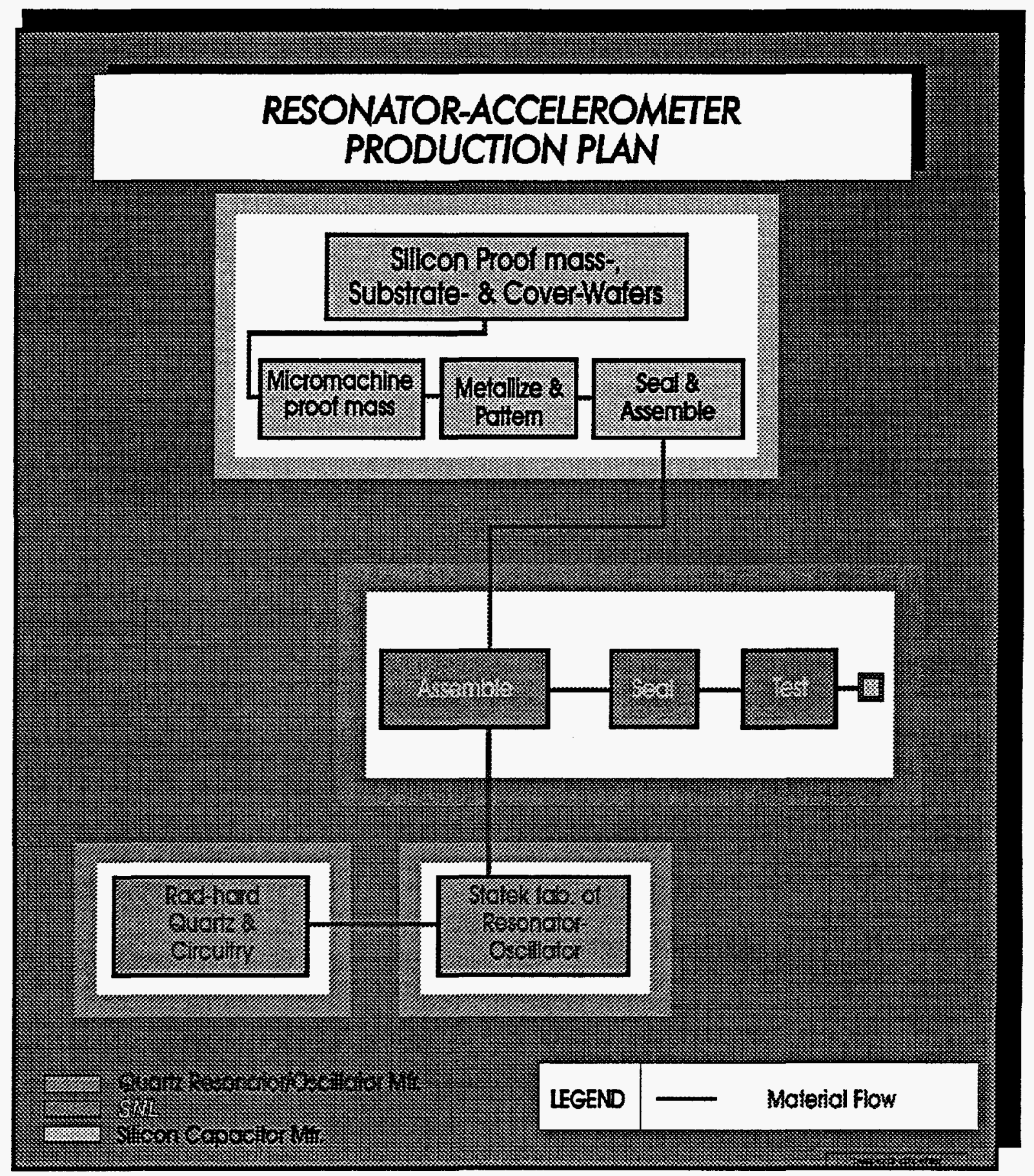

Figure 14. Manufacturing plan. 


\section{Appendix \\ Accelerometer Measurement Errors}

When a frequency-based accelerometer is utilized in a counter configuration, the frequency signal from the accelerometer acts as a gate to a counter, as illustrated in Figure 15 . The counter is turned on (gated) for a predetermined number of periods (see Figure 16), or a predetermined number of counts, $\mathrm{N}$, and a reference clock's frequency is measured. During the time interval determined by these $N$ accelerometer counts, $N(r)$ clock counts are recorded.

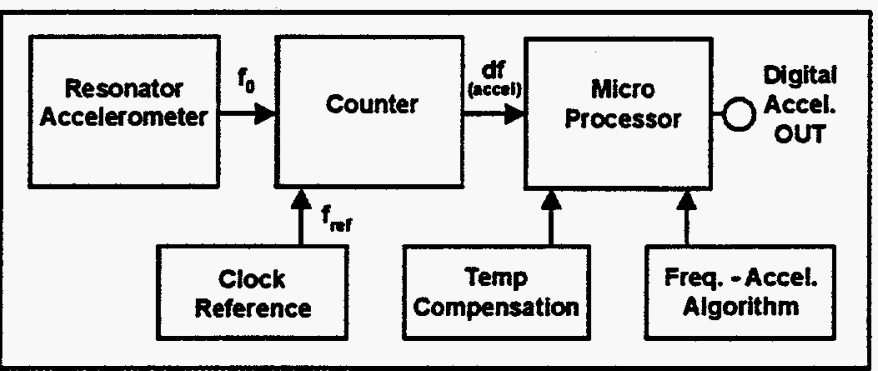

Figure 15. Accelerometer block diagram.

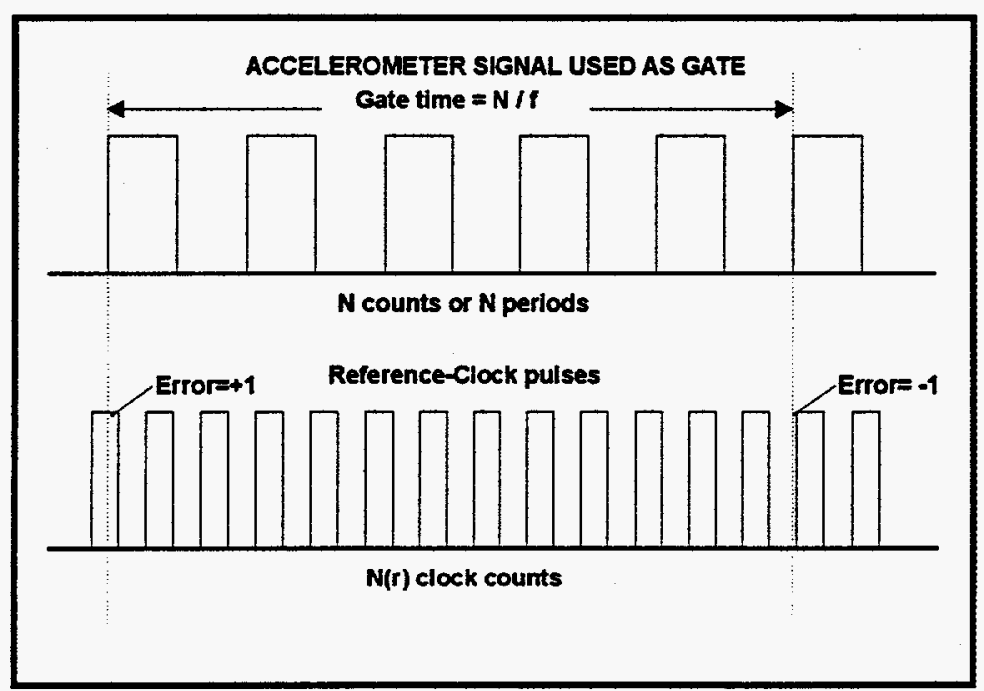

Figure 16. Timing signals.

The unknown frequency, $f$, being measured, is then calculated as $f=f_{r} * N / N(r)$ where $f_{r}$ is the known clock frequency. The time period during which the $\mathrm{N}$ counts are recorded is usually called the gate time with an associated gate frequency, $f_{g}$. 
The total differential of this expression, expressed in fractional form, may be used to find the error contributions to from the various measurement error sources;

$$
\Delta \mathrm{f} / \mathrm{f}=\Delta \mathrm{f}_{\mathrm{r}} / \mathrm{f}_{\mathrm{r}}+\Delta \mathrm{N} / \mathrm{N}-\Delta \mathrm{N}(\mathrm{r}) / \mathrm{N}(\mathrm{r}) .
$$

The uncertainty in the reference frequency counts is $\Delta \mathrm{N}(\mathrm{r})= \pm 1$ count and the reference count, $N(r)$, is the product of the clock frequency $f_{r}$ and the gate time interval $1 / f_{g}$. Since the counting process is controlled by the predetermined signal count, $\Delta \mathrm{N}$ is zero. The measurement frequency uncertainty therefore becomes

$$
\Delta \mathrm{f} / \mathrm{f}=\Delta \mathrm{f}_{\mathrm{r}} / \mathrm{f}_{\mathrm{r}} \pm \mathrm{f}_{\mathrm{g}} / \mathrm{f}_{\mathrm{r}} .
$$

Typical quartz-controlled clocks exhibit a one-second stability of $\leq 10^{-9}$ with shorter time stabilities determined by the circuit noise and represented as $10^{-9} / \tau$ where $\tau$ is the measuring time interval. Longer-time stabilities are a result of aging processes in the quartz resonator and oscillator circuitry.

At a ten-millisecond measuring time interval, for example, one has $f_{g}=100 \mathrm{~Hz}$. With a clock frequency of $\mathrm{f}_{\mathrm{r}}=25 \mathrm{MHz}$,

$$
\Delta \mathrm{f} / \mathrm{f}=10^{-9} / 10^{-2}+100 / 25(10)^{6}=4.1(10)^{-6} \text {. }
$$

In trajectory sensing applications, however, the accelerometer is used in an integrating fashion where a velocity increment and ultimately a length increment are measured. In this mode, although shorter time measurements can be taken, no counts are jettisoned and the total path time becomes the equivalent measurement time. For example, for a 10 -second flight measurement time, the measurement uncertainty is

$$
\Delta \mathrm{f} / \mathrm{f}=10^{-9} / 10+0.1 / 25(10)^{6}=4.1(10)^{-9} .
$$

At a scale factor of $4 \mathrm{ppm} / \mathrm{g}$, this is an error of 1 milli-' $\mathrm{g}$ '. 
DISTRIBUTION:

$\begin{array}{llll}1 & \text { MS1070 } & 1200 & \text { Raymond Bair } \\ 1 & \text { MS0523 } & 1204 & \text { Charles Gibbon } \\ 1 & \text { MS1071 } & 1205 & \text { T.J. Allard } \\ 1 & \text { MS0527 } & 1235 & \text { Thomas Fischer } \\ 5 & \text { MS0527 } & 1235 & \text { Dale Koehler } \\ 1 & \text { MS1079 } & 1300 & \text { Al Romig } \\ 1 & \text { MS0351 } & 1307 & \text { Marion Scott } \\ 1 & \text { MS0603 } & 1322 & \text { Thomas Zipperian } \\ 1 & \text { MS0603 } & 1322 & \text { Stanley Kravitz } \\ 1 & \text { MS1078 } & 1321 & \text { Harry Weaver } \\ 1 & \text { MS1080 } & 1325 & \text { Paul Mcwhorter } \\ 1 & \text { MS1080 } & 1325 & \text { Jim Smith } \\ 1 & \text { MS1082 } & 1333 & \text { David Palmer } \\ 1 & \text { MS1082 } & 1333 & \text { Cathleen Reber } \\ 1 & \text { MS1082 } & 1333 & \text { Katherine Myers } \\ 1 & \text { MS0960 } & 1400 & \text { Jimmie Searcy } \\ 1 & \text { MS0957 } & 1411 & \text { Gerald Cessac } \\ 1 & \text { MS0957 } & 1411 & \text { David Norwood } \\ 1 & \text { MS0958 } & 1471 & \text { John Ledman } \\ 1 & \text { MS0958 } & 1471 & \text { Charles Walker } \\ 1 & \text { MS1435 } & 1800 & \text { Harry Saxton } \\ 1 & \text { MS0340 } & 1831 & \text { Michael Cieslak } \\ 1 & \text { MS0340 } & 1831 & \text { Paul Vianco } \\ 1 & \text { MS0952 } & 2151 & \text { Phil Bennett } \\ 1 & \text { MS0505 } & 2334 & \text { G. Michael Heck } \\ 1 & \text { MS0985 } & 2602 & \text { Michael Callahan } \\ 1 & \text { MS1380 } & 4211 & \text { Angelo Salamone } \\ 1 & \text { MS0479 } & 5151 & \text { Donald Tipton } \\ 1 & \text { MS0475 } & 5153 & \text { Frank Dean } \\ 1 & \text { MS0475 } & 5153 & \text { Mike Senglaub } \\ 1 & \text { MS0445 } & 5166 & \text { Ronald Hartwig } \\ 1 & \text { MS0445 } & 5166 & \text { Thomas Hendrickson } \\ 1 & \text { MS0445 } & 5166 & \text { Kent Meeks } \\ 1 & \text { MS0570 } & 5900 & \text { K. David Nokes } \\ 1 & \text { MS0877 } & 5903 & \text { James Gosler } \\ 5 & \text { MS0877 } & 5932 & \text { John Anthes } \\ 1 & \text { MS9018 } & 8523-2 & \text { Central Technical Files } \\ 5 & \text { MS0899 } & 4414 & \text { Technical Library } \\ 1 & \text { MS0619 } & 12615 & \text { Print Media } \\ 2 & \text { MS0100 } & 7613-2 & \text { Document Processing, for DOE/OSTI }\end{array}$

